\title{
Urban Storm Flooding: Characteristics and Management in Beijing
}

\author{
FU Chao-chen ${ }^{1,2}$, LIU Jia-hong ${ }^{3}$, WANG Hao ${ }^{3}$, XIANG Chen-yao ${ }^{3}$, FU Xiao-ran ${ }^{4}$, LUAN Qing-hua ${ }^{1}$ \\ ${ }^{1}$ School of Water Conservancy and Hydroelectric Power,Hebei University of Engineering,Handan 056038,China; \\ ${ }^{2}$ Drainage Management Department,Beijing Water Authority,Beijing 100038,China; \\ ${ }^{3}$ China Institute of Water Resours and Hydropower Research,Beijing 100038,China; \\ ${ }^{4}$ College of Architecture and Civil Engineering, Beijing University of Technology, Beijing 100124, China
}

\begin{abstract}
Beijing is located on the North China Plain with five rivers, which belong to the Hai River Basin. Its continental monsoon climate with uneven precipitation distribution is extreme likely lead to serious urban flood disasters. According to the disaster results, urban storm flood in Beijing can be classified into four types. Here typical extreme storm flood events and their characteristics in Beijing were analyzed in detail. It showed that storm flood events in recently decades had a trend, which centered in a relatively small area with high intensity and short duration. The main reasons of urban storm flood disaster were urbanization and basic facilities with low flood and drainage standard. Urbanization means land utilization significantly altering hydraulic processes, and extreme storm can easily exceed those facilities capacity. In order to deal with urban storm flood, Beijing government have taken four measurements, which were upgrading and reconstruction of rainwater pumping stations, improving projects of small and medium rivers, building sponge city, and implementing the West Suburb Storm-water Regulation Project. In addition, the flood warning and emergency management system has been established. Furthermore, some measurements were pointed to be done in the future, including improvement of the flood control management system, improvement of flood control plans, strengthening flood warning system, and strengthening social management and public awareness of flood prevention. With these improvements of management and engineering measurements, it can be more secure under intensive storms in Beijing. These experiences of flood control in Beijing can provide references for other cities.
\end{abstract}

\section{Urban storm flood events and the causes in Beijing}

Beijing is located on the northwest end of the North China Plain. The terrain inclines towards the northwest. It covers $16400 \mathrm{~km}^{2}$ in total, with the urban area of 1381 $\mathrm{km}^{2}$ (approximately $8 \%$ of the total area). Five rivers flows through Beijing (namely, Juma River from the Qing River, Yongding River, the North Canal, Chaobai River and Juhe River from Jiyun River), and they are all parts of the Hai River Basin. 


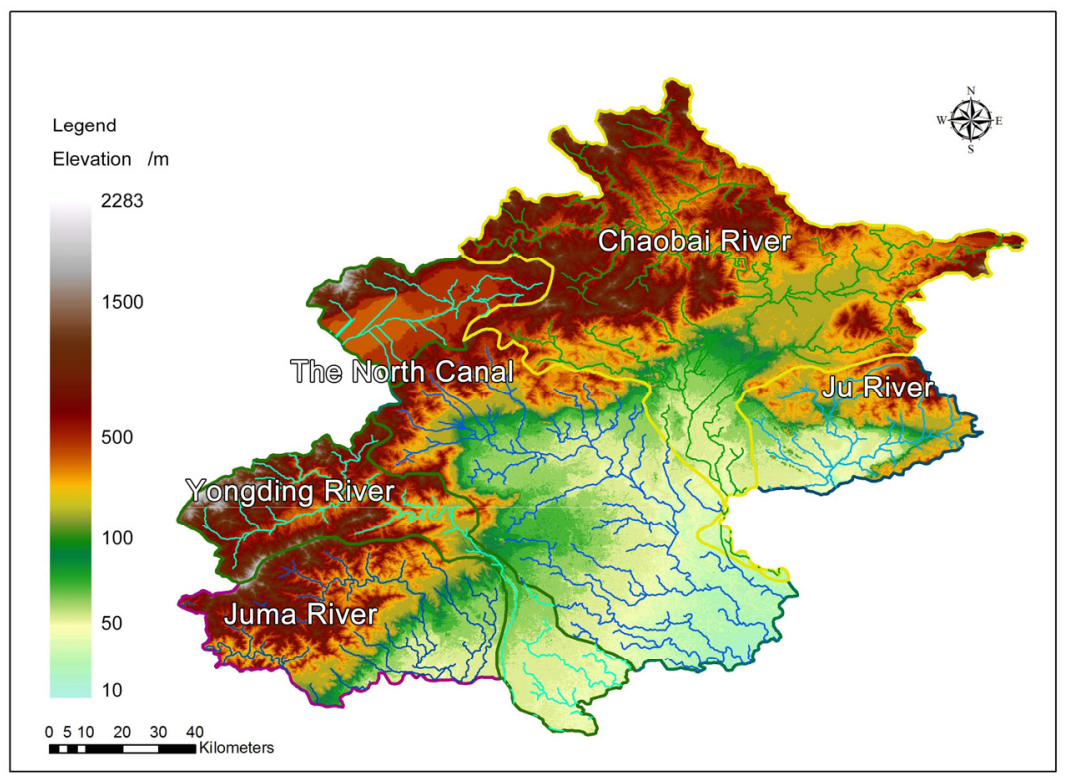

Fig 1. Catchment division of Beijing

In order to drain the flood in the central urban districts as quickly as possible, water bodies such as inner-city rivers or lakes are used for storage, and facilities such as water gates or dams are used for controlling $^{[1]}$. The management protocol follows 3 principles: storage in the west, drainage to the east, and diversion in the north and the south. Storage in the west means that, the flood from the upper region of the North Canal catchment is led to creeks and lakes of the Yongding River in order to reduce the draining pressure on the midstream and downstream regions, and the small floods in the Yongding River are retained by a reservoir before a barrage for recycling. Drainage to the east means that, the flood from the upper and middle region of the city are led through creeks into the North Canal. Diversion to the south means that when the south moat is under full capacity, the rubber dam is filled and the sluice is opened so that the flow is led via Liangshui River to the North Canal. Diversion to the north means that when draining pressure is heavy in the northwest of the city, the flood is distracted towards the northeast through 3 routes: 1) to the Qing River through 3 barrages, 2) to the Qing River through 2 creeks and 1 barrage, and 3) to $\mathrm{Ba}$ River through 1 floodgate and 1 sluice.

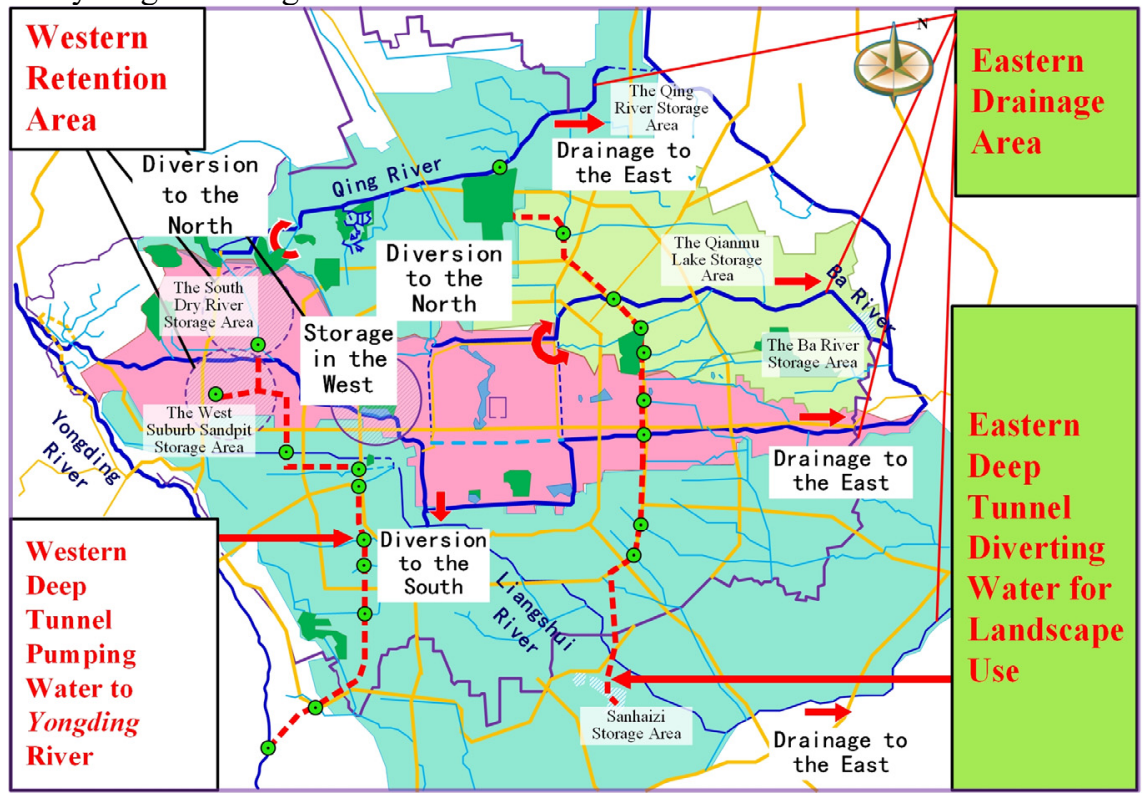

Fig 2. The flood control configuration in the central districts of Beijing

Beijing has a typical temperate continental monsoon climate, with uneven precipitation distribution. Precipitation in the wet season is over $80 \%$ of annual precipitation, and is usually brought by several storms between late July and early August. This climate is extremely likely to cause storm flood disasters, threatening economic and personnel safety. 


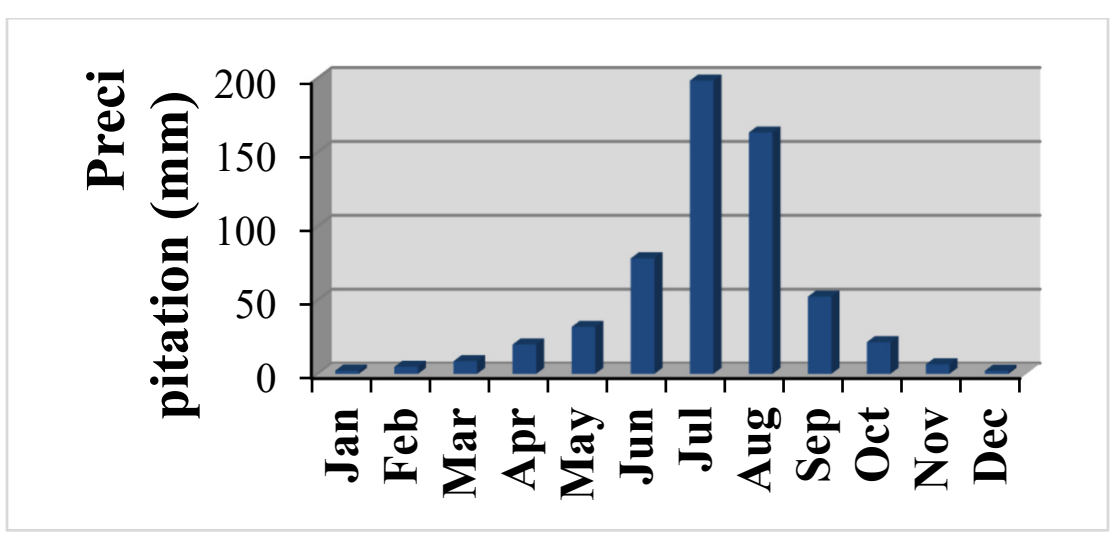

Fig 3. Temporal distribution of the precipitation in Beijing

The flood disasters brought by storms in Beijing can be classified into 4 types: 1) water logging disasters in urban areas, which includes fluvial floods, large scale water logging, traffic paralysis, old building collapse, water intake by underground facilities, and related blackout and water cut-off; 2) flood disasters in reservoirs and big rivers, including piping, cracks, dam collapse, superflux, breach, inrush, river rise and other risks of important flood control facilities; 3) water logging in the outskirts and related secondary disasters; 4) induced disasters in rural areas, including torrential floods, mudslide, landslide, ground collapse and so on.

\subsection{Characteristics of the extreme storm events in Beijing}

Analysis on the frequencies of storms in Beijing region in the recent 5 decades shows the following (Figure 4).
(1) Regional storms, which means that all areas in Beijing received over $25 \mathrm{~mm}$ rainfall within 24 hours, occurred more frequently before 1980, happening 6 8 times annually; after 1980, the precipitation in Beijing region decreased notably, as well as the occurrence of regional storms, down to 5 times a year.

(2) In the recent decade, the storms in Beijing region have been showing new patterns. The storm of this kind is created by one single small-scale cumulonimbus cloud or a rain cell, and concentrates on a small area. This weather is more random, and it appears/disappears very quickly, which adds difficulty to forecasting. They could easily cause local water logging and traffic paralysis.

(3) According to statistics from 2003 2012, the short-duration extreme storms that poured over $70 \mathrm{~mm}$ rainfall in 1 hour happened 82 times in the last ten years. The figure tended to climb after 2000, as well as the intensity of these storms.

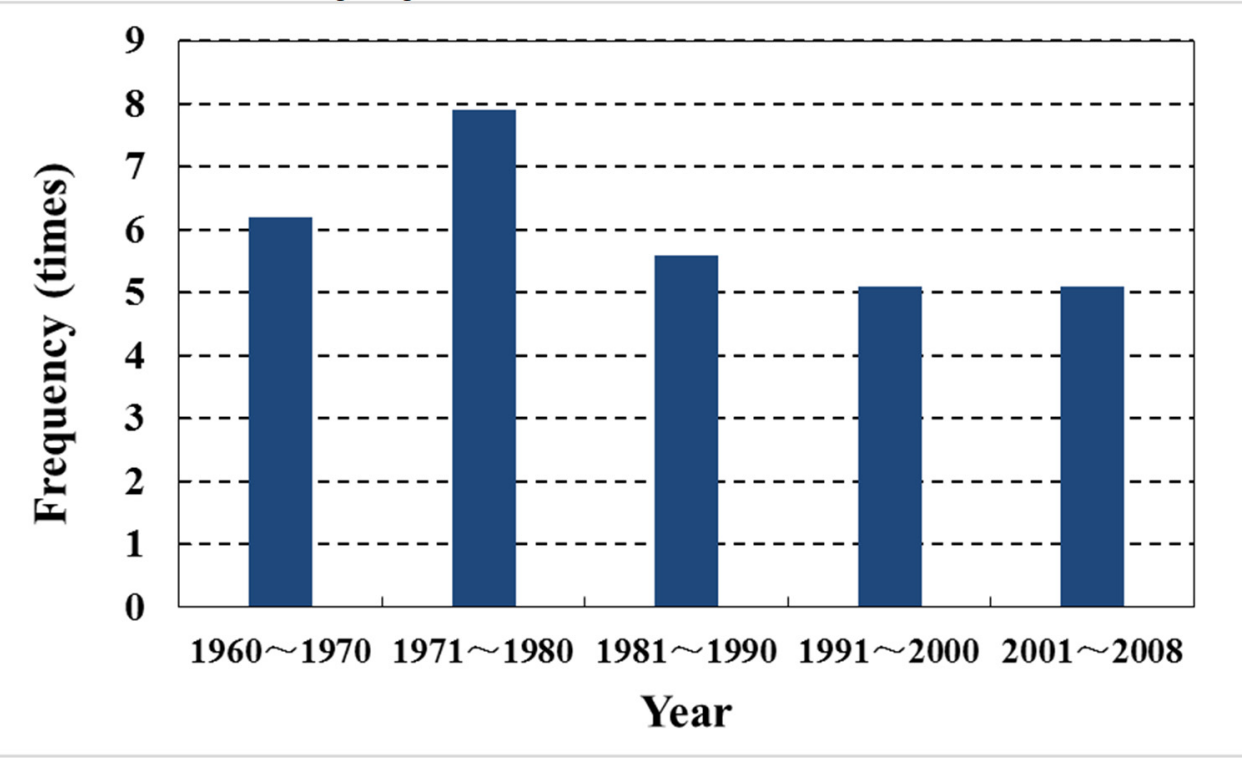

Fig 4. The temporal trend of frequencies of storms in Beijing region

\subsection{Causes of the pluvial flood disasters in Beijing}

\subsubsection{Urban development}

The changes in land utilization significantly altered hydraulic processes such as canopy interception, evaporation, transpiration and infiltration. Road construction disturbed the natural surface draining system, and affected the runoff process. While urban impervious area expands, grassland, woods, farmland and water bodies all shrink. As a result, the runoff coefficient increases. The alteration of ground surface in urban areas and the new rainfall-runoff pattern 
accompany are one important factor of extreme storm-flood event ${ }^{\mathrm{s}[2]}$.

According to statistic data, the impervious area in the central Beijing districts increased from $60 \%$ in 1960 s to the current $85 \%$, while the area of water surface decreased by $80 \mathrm{hm}^{2}$. This means that natural storage volume decreased $400000 \mathrm{~m}^{3}$ for an average water depth of $0.5 \mathrm{~m}$. The shrink of water bodies directly caused surface runoff increase and consequently the higher pressure in urban pipeline systems.

Table 1. Comparison of the flood event on "12.07.21" and the one on "63.08.09" at the Lejia Garden Station

\begin{tabular}{|c|c|c|c|c|c|c|}
\hline Event & $\begin{array}{c}\text { Rainfall } \\
\text { depth (mm) }\end{array}$ & $\begin{array}{c}\text { Runoff } \\
\text { depth (mm) }\end{array}$ & $\begin{array}{c}\text { Runoff } \\
\text { coefficient }\end{array}$ & $\begin{array}{c}\text { Peak } \\
\text { time } \\
(\mathrm{h})\end{array}$ & $\begin{array}{c}\text { Flood duration } \\
(\mathrm{h})\end{array}$ & $\begin{array}{c}\text { Peak flow } \\
\left(\mathrm{m}^{3} / \mathrm{s}\right)\end{array}$ \\
\hline 630809 & 359.1 & 187.3 & 0.52 & 20 & 44 & 261 \\
\hline 120721 & 197 & 106.4 & 0.54 & 7 & 16 & 440 \\
\hline
\end{tabular}

\subsubsection{Low flood and drainage standard in the city}

Currently, the flood prevention standard of the whole city is to resist storms of 200-year return period (mainly focusing on Yongding River), and that of the four main inner rivers are the 20-year storm, the 50 -year storm or the 100-year storm. However, for the basic hydrological units of urban catchments, such as residential quarters, rainwater drainers, roads and flyovers, the standard design storm is usually the 1 -year event. For important roads, areas or where even short water logging could cause serious damage ${ }^{[3]}$, the standard design storm is usually the 3-year 5-year event, and for particularly important regions that is the 5-year 10 -year event. If the intensity of a short-duration storm exceeds that of the ten-year event (i.e. per hour precipitation exceeds 65 $\mathrm{mm})$, the urban drainage system would exceed its capacity and there would occur water logging ${ }^{[4,5]}$.

\section{Urban flood management of Beijing}

The establishment of the flood prevention standard is a systematic issue. Firstly, the drainage system is usually consisted of subcatchments, rain grates, rain drainers, branch drains, main drains, riverways and pumping stations if the drainage area is low ${ }^{[6]}$. Any problem in part can cause inefficient drainage or water logging in the system. Secondly, the drainage capacity depends on that of the receiving river, which depends on the capacity and conditions of the downstream river ${ }^{[7]}$.

The extreme storms in Beijing in recent years are typically short-duration, highly intensive and concentrated, which brings new challenges to traditional urban drainage system. Therefore, reconstruction on drainage systems, storage infrastructures and riverways
Moreover, rapid urban development caused heat island effect in central Beijing and several big cities nearby. The strong thermal updraft confronts high-level cold air and creates rainfall that concentrates on urban areas. In comparison, the surrounding rural areas received less rainfall.

Taking Lejia Garden Station on Tonghui River as an example, the flood event on July $21^{\text {st }}, 2012$ and the one on August $9^{\text {th }}, 1963$ are compared as shown in Table 2. is needed in response to the new problems.

\subsection{Upgrading and reconstruction of rainwater pumping stations}

In Beijing there are 192 rainwater pumping stations, which are able to drain $2,360,000 \mathrm{~m}^{3} / \mathrm{h}$. These rainwater stations are mostly built along with roads or flyovers in different periods, so they were designed according to very different standards. For example, nighty rainwater stations are in the central districts. For 4 stations (4\%) among them, the design rains are one-year events; those for 81 stations $(90 \%)$ are 2 or 3-year events, and 5 stations $(6 \%)$ are designed according to five-year events. However in recent years the storms that pour over $70 \mathrm{~mm}$ rainfall per hour occur more frequently, and most stations are overwhelmed.

In addition, runoff coefficient has increased along with the expansion of hard ground. In last five years, urban surface runoff coefficient has increased by $15 \%$, from 0.55 to 0.63 . Catchment areas, especially around flyovers, are flooded by more water that exceeds the capacity of water pumps and faced water logging.

To secure the safety of the city, Beijing launched the "Three-year Project of Rainwater Pumping Stations Upgrading and Rainwater Harvesting in Beijing Urban Districts" in 2013. The project has upgraded 77 pumping stations at low-ground flyovers in different groups. The project reconstructed rainwater harvesting systems, enlarged water pumps (enlarging the total pumping capacity from $374,000 \mathrm{~m} 3 / \mathrm{h}$ to $718,000 \mathrm{~m} 3 / \mathrm{s}$ ), build 60 new storage tanks (create $210,000 \mathrm{~m} 3$ storage volume) and drainage pipelines. The goal of the implementation is to keep the main roads clear under ten-year storms. Besides, new storage tanks built under greenbelts, parks, parking lots can harvest rainwater for recycling. 


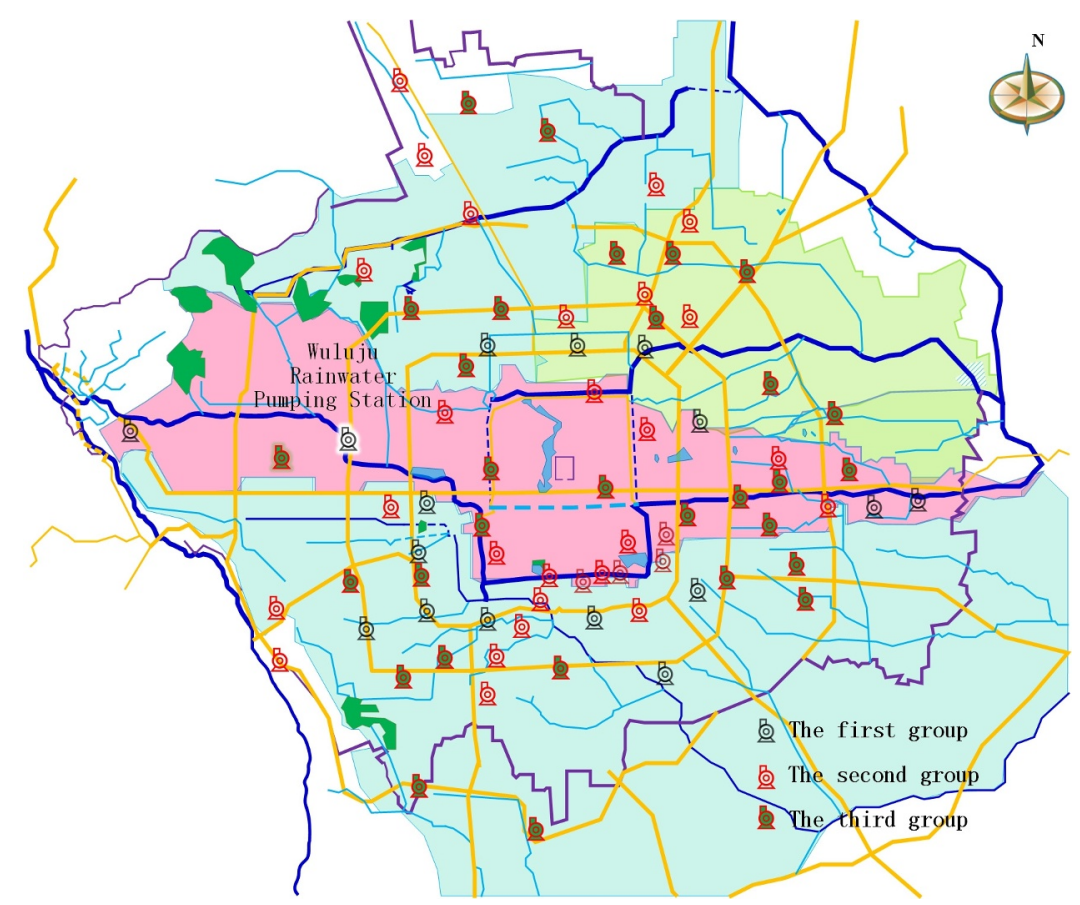

Fig 5. Rebuilt pumps in Beijing central districts

Example: Upgrading in Wuluju Rainwater

\section{Pumping Station}

The Wuluju Rainwater Pumping Station Upgrading Project has been finished and is ready to be used. This project included rainwater harvesting system reconstruction, water pump enhancement, new storage tank and drainage pipeline construction. Because the upgrade projects of rainwater pumping stations were usually at corners of districts or busy traffic spots, the construction sites were very limited. To deal with this problem, pipe-jacking construction was applied. Two pipes of $3 \mathrm{~m}$ diameter, $150 \mathrm{~m}$ length were set as storage tanks, able to store $2090 \mathrm{~m}^{3}$ water. This method significantly reduced the work of land requisition and saved the cost.

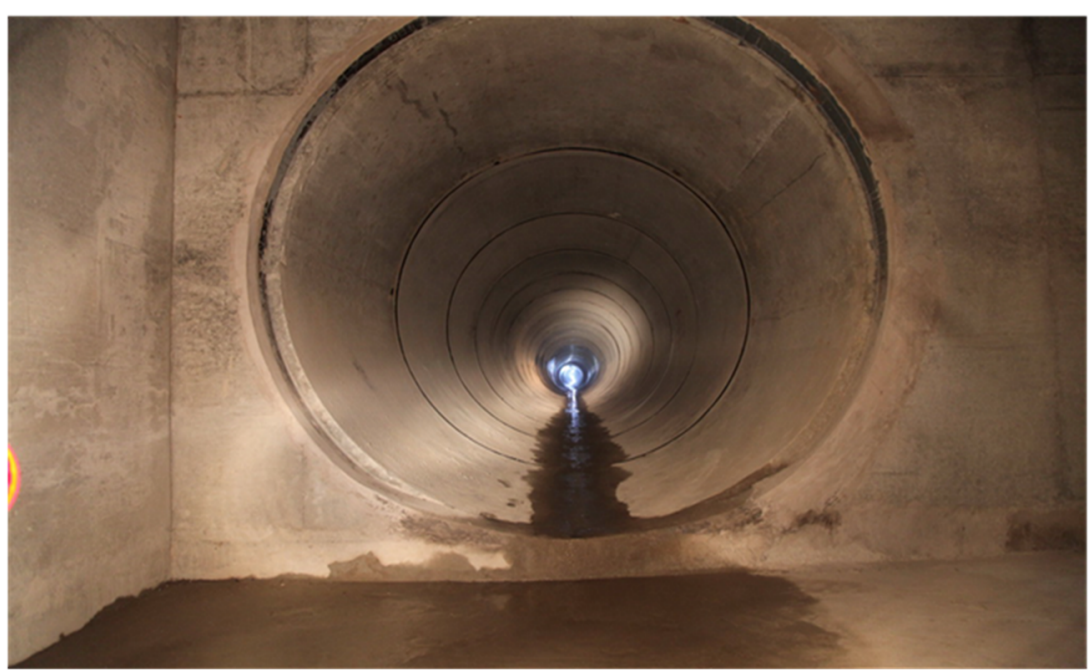

Fig 6. A $3 \mathrm{~m}$-diameter drainer and storage tank at the Wuluju Rainwater Pumping Station

\subsection{Improvement projects of small/medium rivers}

There are $425 \mathrm{small} /$ medium rivers of $6448 \mathrm{~km}$ length in total in Beijing. The ungoverned rivers were usually polluted and unable to drain efficiently. To deal with this problem, Beijing announced "Beijing Implementation and Construction Plan for Hydraulic Engineering" in 2013, organizing the dredging and improvement on 1460 $\mathrm{km}$ river channels where flood risks were high, or infrastructures were weak, or population was large, or there was important objects. Riverways were properly connected to surrounding underground drainage pipelines, improving the flood prevention standard from under the 5-year event to over the 10-year event or 20 -year event.

The management of small or medium rivers has four approaches: via infiltration, storage, retention or drainage. The specific method highly depends on local urban-rural layout, the economic conditions and social environment. Urban channels' primary problem is the disconnection of water bodies and pollution. For plain rivers managers should build water networks based on natural conditions. 
For rivers in mountainous regions, the villages and roads along the rivers should be key protections, and flood water should be channeled out with full respect to local natural landscape.

Moreover, riverway management should be consistent and integrated with six tasks: (1) pollution control; (2) water body connection; (3) the South-to-North Water Diversion Project and groundwater recharge; (4) the construction of flood detention and storage areas; (5) water-soil conservation and afforestation on plain regions; (6) greenbelt construction and tourism development.

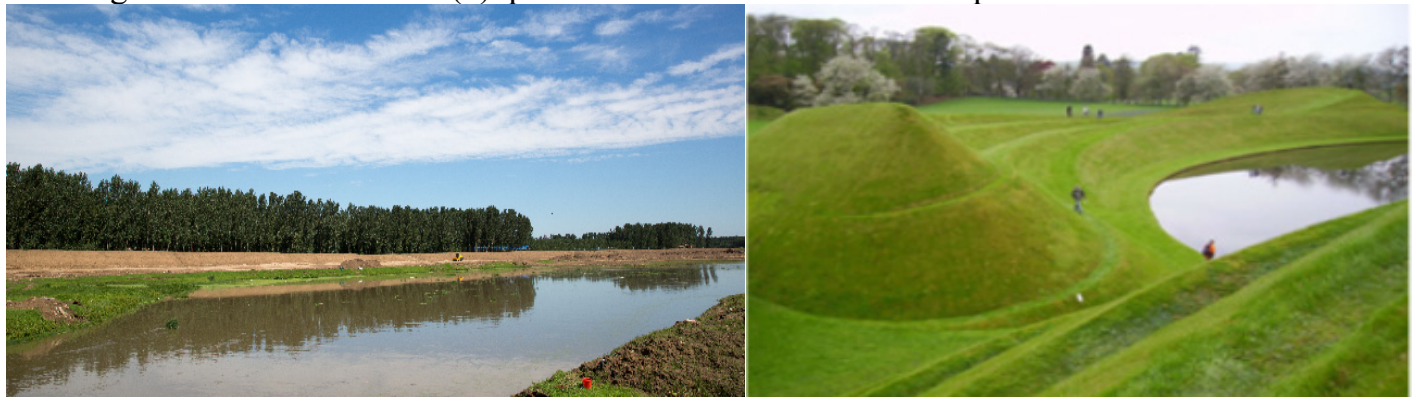

Fig 7. Construction sites

\subsection{Sponge City Construction}

The construction of sponge cities is comprehensive, systematic engineering. It implicates Low Impact Development, drainage and flood prevention, rainwater reuse, groundwater restoration, flood disaster relief and other fields. It requires taking precedence over rainwater harvest and using natural routes to drain rainwater, to purify rainwater or to allow infiltration when improving urban drainage systems. In the philosophy of sponge city construction, the impact of urban development on ecological environment should be limited to the minimum. The aim is to avoid waterlogging and pluvial flood disasters in non-extreme rain events, to clear malodorous, black rivers, and to relieve the urban heat island effect ${ }^{[8]}$.

For a sponge-city built-up region, on less than $70 \%$ of annual precipitation should be retained or reused locally ${ }^{[9]}$. For instance, urban green spaces should be able to absorb all the rainwater falling onto them, and take in the surface runoff from surrounding impervious areas to their maximum capacities ${ }^{[10,11]}$. Roads and plazas should collect, purify and reuse rainwaters, lifting pressure on the drainage system. By 2020, the sponge-city region is supposed to be no less than $20 \%$ of the built-up area, and the figure is $80 \%$ by 2030 . New constructions or districts should be planned and built up to the sponge-city standard, while old urban areas should be transformed gradually.

\subsection{The West Suburb Stormwater Regulation Project}

The West Suburb Sandpit Construction was one of the key parts in the flood prevention regulation of the central districts. The water division by a control sluice ensures the drainage in three catchments (about $27 \mathrm{~km}^{2}$ ) under 100 -year storms. The construction included the sluice and two buried culverts that connected two sandpits individually. The larger sandpit is $680,000 \mathrm{~m}^{3}$ and able to contain $700,000 \mathrm{~m}^{3}$ water.

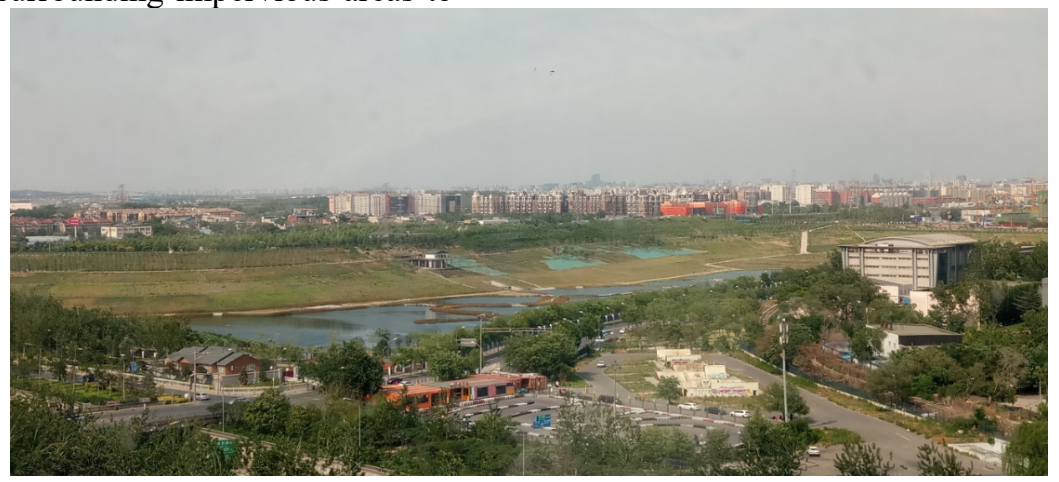




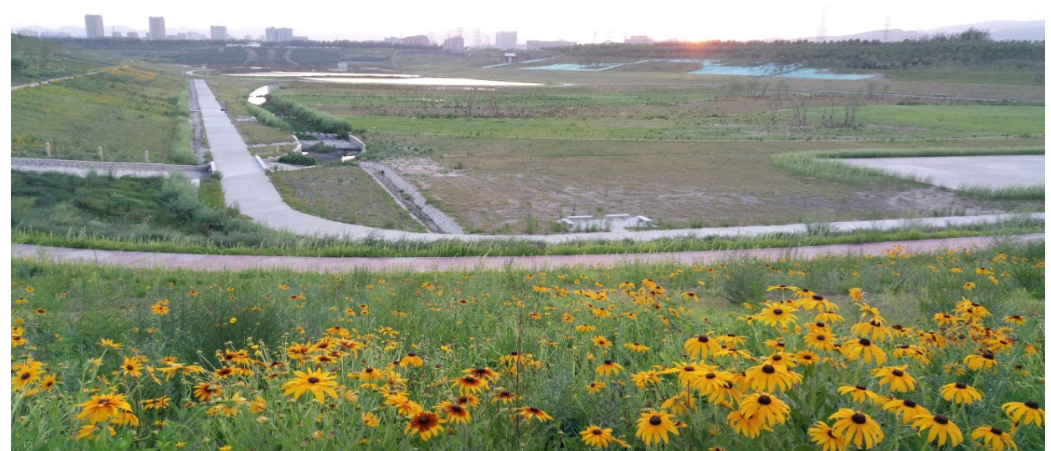

Fig 8.Before-and-after comparison of the West Suburb Sandpit Project

\section{Urban pluvial flood warning and emergency management}

Storms in recent years have brought extraordinary casualties and economic loss, which exposed problems such as weakness in flood prevention facilities, deficiency of equipment and stocks for emergencies, late statistic reports, narrow warning coverage, defective command systems and people's weak awareness of flood disasters $^{[12]}$. Learning from experiences, Beijing established a new flood prevention command system called " $1+7+5+16$ ".

The " 1 " means strengthening command effectiveness over flood prevention work. Beijing established the flood prevention headquarters that organizes the entire flood response operation, and the deputy mayor takes charge.

The "7" means establishing 7 branch units to manage flood prevention in specific fields, namely publicity, housing and construction, traffic, underground systems, geological disasters, tourist attractions and integrate support. The housing and construction branch helps all buildings, ongoing constructions, general underground facilities through floods safely. The traffic branch guarantees the safety in roads and urban rails during storms. The underground system branch focus on protection and emergency management for water, electricity, gas, heat supply and other vital supply lines. The geological disaster branch takes charge in the precaution and controlling over areas liable to geological disasters and goaves. The tourist attraction branch takes charge in the flood prevention at tourist attractions. The integrate support branch organize and coordinate all the branches in general. The publicity branch improve public awareness of urban flood disasters and related self-rescue education.

The "5" means strengthening protection construction along 5 main rivers. Five command offices have been established for organizing and supervising the flood prevention, emergency rescue and disaster relief work in Yongding River catchment, Chaobai River catchement, the North Canal catchment, the Qing River catchment and Ji River catchment.

The "16" means placing responsibilities on 16 county administrative chiefs. The county command offices organize and supervise all flood disaster prevention and response work within the county boundary.
Flood control discussion and announcement protocols were also improved. The discussion system with meteorological departments and a flood season news release system were established to normalize flood warning announcement work $^{[13]}$. A basin cooperation system was established to help counties in the same basin unit and deal with flood disasters together. For key targets of flood prevention, governments, industries, operation units should collaborate on planning, teamwork, safety measures and disaster relief ${ }^{[14]}$. Army and armed police force should be also united on flood control work, especially in extreme events. The supervisory work and the responsibility investigation system should be improved. Officers who do not perform their duties should be called to account. The principles are "unified command, unified dispatching, unified decision making". Oversight should be strengthened and measures such as self-examination and inter-checking should be taken. The implementation of responsibility system, planning, teamwork, emergency commodity, safety measures, publicity, training and exercise should be checked ${ }^{[15]}$. Flood drills of different types, patterns and in different regions should be carried out. Emergency precaution should be improved. The release of warning information should be enhanced, and the flood response plans should be operable ${ }^{[16]}$. The emergency commodities should be secured and necessary founding should be guaranteed. The operation and maintenance of hydraulic engineering facilities should be ensured.

The Internet technology, the Internet of Things, and the Intelligent Water Network were also applied. Automate remote monitoring systems were built for urban drainage infrastructures. Dense hydrological monitoring on urban roads, blocks, lakes and other water bodies, as well as monitoring over rainwater drainage pipelines, enables real-time knowledge about urban storm and flood disaster conditions, which is the basis for quicker emergency management.

\section{The prospect of urban flood management in Beijing}

The flood prevention of Beijing is related to the reform and development of the capital of China, so it is particularly important to improve the quality of flood control work. 


\subsection{Further improvement of the flood control management system}

Firstly, Beijing should strengthen the " $1+7+5+16$ " command system to realize the river basin management. It is also important to implement monitoring and communication mechanisms. To achieve that goal, Beijing will improve the system and regulation protocols.

Secondly, the work of flood prevention management should be divided and classified. Both normal and emergency working system should be established, standardized and institutionalized.

Thirdly, Beijing should make the rescue team more specialized and professional. Meanwhile, social volunteers be united, establishing a linkage mechanism.

\subsection{Further improvement of flood control plans}

Firstly, risk assessments should be conducted for key areas. To secure the safety of people and transport facilities, the risk assessment should be conducted at the weak spots, especially the overpass and underground space.

Secondly, linkage mechanism should be built between departments, especially for the management of emergencies at public places, such as the main transport stations, airports and train stations ${ }^{[18]}$. If there are large quantities of passengers stranded in those places, related departments are responsible for taking steps to resettle passengers.

Thirdly, supervisory mechanism should be built. The responsibility system is that the head of the department is the first person responsible. The execution of flood control plans and emergency response should be specified, insuring the measures and information can be transferred to towns, sub-districts, villages and people.

Fourthly, professional plan for flood regulation should be improved. The detailed regulation mode for regional rainfall or medium/small rains should be developed. The plan's foundation is risk assessment; its basic is the hydrologic forecasting and its measure is scheduling model. Beijing should make an elaborate scheduling model for water system connecting rivers and lakes, and also make emergency measures for floor drain.

\subsection{Further strengthening flood warning system}

Firstly, the work system of warning dissemination should be improved, including the targets, the standards, the programs, the region identification and the content. Beijing should build the joint work system and its regulations for disaster prevention. It is important to guarantee the efficient co-operation between departments.

Secondly, the government should further mobilize the society. Governments at all levels should intensified their effort and clarify responsibilities in aspects such as publicity of warning and disaster relief knowledge, the government order, job deployment and media announcement. The information from weather, traffic, land and traffic management should be integrated to realize the all-around and multi-channel warning information publish.

Thirdly, the ways in which warning information is transferred to the public should be diverse. Radio, television, websites, newspapers, micro blogs and mobile phone messages should all be included. The message should also be easy to understand. Beijing will comprehensively improve the capacity, timeliness and coverage of the flood warnings release. Before the advent of disaster, the warning messages will be transferred to every citizen.

Fourthly, the research on flood control should be conducted, to improve the judgment of magnitude and risk of storms. Weather forecast and discussion work should be reinforced, especially for the risk assessment on all kinds of rainfall regime, to deploy flood control work and the rescue force easily. In a word, more research should be conducted on the patterns of heavy rains and floods, realizing the more elaborate and precise warning system.

\subsection{Further strengthening social management and public awareness of flood prevention}

Urban flood control is not only a technical work, but also a social management work. Social management and the education of public awareness of flood prevention should be directed to the citizens.

Firstly, all members of society should pay more attention to flood prevention and flood control ${ }^{[18]}$. Governments should give positive guidance to let all sectors take part voluntarily. The popularization of knowledge of flood control and disaster relief is also very important. The main point is to enhance the risk aversion ability and self-rescuing ability of the public, the strain ability of the staffs, the commanding ability of new leaders, the cooperative ability of sectors, and the emergency capacity of rescue teams.

Secondly, the norm mechanism of social management should be built up and all kinds of contingency plans should be made. Effective cooperation should be achieved. Flood drills should be normalized and popularized. Governments should build volunteer teams and try to cover all counties and villages. The volunteers should be trained systematically under the guidance of professionals.

Thirdly, particular attention should be paid to the publicity and education on public awareness of flood prevention and disaster relief. The self-saving awareness and ability of citizens should be improved, especially students, mountain villagers, people in rural-urban continuum, outlanders and migrant population.

Fourthly, posters, brochures, public service advertisements, the Internet, microblogs, radio, television, street newspapers and billboard should be adopted to disseminate knowledge of flood prevention and mitigation ${ }^{[19]}$. We should try to cover every company, every school, every scenic spot, every village, every community and every family. Knowledge of flood prevention and safety should be transferred to squares, to 
streets, to family and to every citizen.

\section{Acknowledgements}

The researchers thank the Chinese National Natural Science Foundation (No.51739011 \& No. 51522907) and the National Key Research and Development Program of China (2016YFC0401401) for their support of this study. The study was also supported by the Open Research Fund of the State Key Laboratory of Simulation and Regulation of Water Cycle in River Basin at the China Institute of Water Resources and Hydropower Research (No. 2017ZY02). Beijing Water Affairs Bureau has given a lot of help when the paper was prepared, which is particularly grateful.

\section{Reference}

1. Xie Yanfang. Discussion on emergency response mechanism of flood control in Beijing[J].Beijing Water, 2014(4):46-48,58.

2. Wang Yi. Main causes and Countermeasures of urban flood disaster in Beijing[J]. China Flood and Drought Management, 2011,21 (6) : 27-28.

3. Liu Hongwei, Liu Shu, Zhu Jinliang, Yin Yue, Li Yuchen. Discussion on the crux of urban waterlogging and policy suggestions[J]. China Flood and Drought Management, 2011,21 (6) : 27-28.

4. Hou Lei. Reflections on City Waterlogging Disaster Emergency Management and Its Countermeasures[J]. Public Administration and Law, 2015,(01):5-9.

5. Suriya S, Mudgal B V. Impact of urbanization on flooding: the Thirusoolam sub watershed: A case study. Journal of Hydrology, 2012, 412: 210-219.

6. Shi P J, Du J, Ji M X. Urban risk assessment research of major natural disasters in China[J]. Advances in Earth Science. 2006, 21(2): 170-177.

7. Debo.T N, Reese A. Municipal Storm Water Management[M]. United States: The Chemical Rubber Company (CRC) Press, 2002.

8. Liu Dasheng. Water supply: China's sponge cities to soak up rainwater.[J]. Nature,2016,537(7620):.

9. Yun-Fang Ning,Wen-Yi Dong,Lu-Sheng Lin,Qian Zhang. Analyzing the causes of urban waterlogging and sponge city technology in China[J]. IOP Conference Series: Earth and Environmental Science, 2017,59(1): .

10. Wen Sheng Zhang,Qian Xie,Ji Jun Zhu,Ming Cong Feng,Bo Hang Liu. The Early Warning and Algorithm Implementation of Urban Road Submergence in Heavy Rains[J]. Applied Mechanics and Materials, 2014,3082(543):.

11. Weiwei Shao,Haixing Zhang,Jiahong Liu,Guiyu Yang,Xiangdong Chen,Zhiyong Yang,Hao Huang. Data Integration and its Application in the Sponge
City Construction of CHINA[J]. Procedia Engineering, 2016,154:

12. Yutao Wang,Mingxing Sun,Baimin Song. Public perceptions of and willingness to pay for sponge city initiatives in China $[\mathrm{J}]$. Resources, Conservation \&amp; Recycling, 2017,122:.

13. Justine Henonin,Beniamino Russo,Ole Mark,Philippe Gourbesville. Real-time urban flood forecasting and modelling - a state of the $\operatorname{art}[\mathrm{J}]$. Journal of Hydroinformatics, 2013,15(3):

14. Rosenthal, Uriel and Alexander Kouzmin. Crisis Management and Institutional Resilience: An.

15. .William J.Petak,Arthur A.Atkisson. Natural hazard risk assessment and public policy[M].New York:Springer-Verlag, 2010.

16. Apel Heiko,Thieken Annegret H,Merz,Bioschl Gunter. A probabilistic modelling system for assessing flood risks[J].Natural Hazards 2006(38):79-100.

17. Ma Yajie, Su Youpo,Liu Ruixing. Preliminary Study on Risk Assessment of Disaster Prevention Parks[M]. Progress in Safety Science and Technology (Vol.V) Part B, Science Press, Science Press USA Inc.2010,1535-1538.

18. Local Capability Self-assessment and Accreditation Tool,Florida Emergency Preparedness Association. September,2002

19. Fantina Tedim,Salete Carvalho. Flood Management Strategies in Frequent and Small Scale Events: Lessons Learned from Amarante (Portugal)[J]. Quaestiones Geographicae, 2010,29(3). 